\title{
Probiotics in Early grades of Hepatic Encephalopathy
}

\author{
Soha A Elhawari ${ }^{1}$, Emad F Hamed ${ }^{2}$ \\ ${ }^{1}$ Tropical Medicine Department, Faculty of Medicine, Zagazig University, Egypt \\ ${ }^{2}$ Internal Medicine Department, Faculty of Medicine, Zagazig University, Egypt.
}

Corresponding author: Soha A Elhawari email:

sohaelhawary@yahoo.com mobile:

$+201064218082$

Received :5/11/2011

Accepted after

revision: $29 / 11 / 2011$

Keywords :

Probiotics,

Encephalopathy, Psychometric tests, Lactobacillus acidophilus
Background and study aim: Modification of intestinal flora, through different mechanisms is regarded as a therapeutic option in management of hepatic encephalopathy. We conducted this study to test the ability of probiotics in treatment of early grades of hepatic encephalopathy in Egypt.

Patients and Methods: One-hundred educated cirrhotic patients without overt hepatic encephalopathy were included. Diagnosis of cirrhosis based on clinical, ultrasonographic and laboratory findings and patients were screened for grade-I and minimal hepatic encephalopathy by psychometric tests. Hepatic encephalopathy was diagnosed if at least one of psychometric tests was abnormal. Thirty patients with abnormal psychometric tests were included in the final analysis. Acidophilus capsules and banana were given to all patients 30 minutes before meals 3 times daily for 2 weeks.
Results: Minimal and grade-I hepatic encephalopathy were found in thirty out of the one hundred screened patients $(30 \%)$. Minimal and grade-I hepatic encephalopathy were more common in Child class C, than in class B and A. Two weeks after Lactobacillus acidophilus intake, patients showed significant improvement in the performance of psychometric tests $(\mathrm{P}<0.001)$ while liver function tests and Child classes did not improve $(\mathrm{P}>0.05)$. Probiotics improved the clinical grades of hepatic encephalopathy; $96.7 \%(n=29)$ of patients showed improvement in clinical grade of hepatic encephalopathy and only one patient $(3.3 \%)$ did not improve $(\mathrm{P}<0.05)$.

Conclusion: Probiotics could be used to treat early grades of hepatic encephalopathy. Child classes and liver functions did not improve significantly after probiotic therapy.

\section{INTRODUCTION}

Probiotics have been defined as viable microorganisms that when ingested have a beneficial effect in the prevention and treatment of specific pathologic conditions [1]. Currently, the best studied probiotics are lactic acid producing bacteria, particularly Lactobacillus and Bifidobacterium species [2]. Probiotics action is mediated through different mechanisms including: modulation of the intestinal microflora composition, increasing numbers of health promoting genera (Lactobacillus and Bifidobaterium) and decreasing numbers of potentially harmful ones (several strains of Clostidium and Enterococcus); blocking the adhesion sites of pathogens; degradation of toxin receptors; reduction of luminal $\mathrm{pH}$; competition for nutrients with gut microbes; production of inhibitory substances e.g. lactic acid; production of protective substances e.g. butyric acid; enhancement of the gut flora metabolic activity; modification of the mucus layer; enhancement of epithelial barrier integrity and finally stimulation of the immune system $[3,4]$. It thus could be used as alternative to or as adjuvant with antibiotics for gut sterilization [5]. Consequently; probiotics were used in treatment of different GIT diseases including lactose intolerance, inflammatory bowel disease, and various types of diarrhea [6].

The general term of hepatic encephalopathy (HE) covers all the neurological and psychological symptoms in patients with liver disease that cannot be explained by the presence of other pathologies. 
It is a clinical syndrome with a wide range of variability extending from minimal impairment of intellectual function only detectable by psychometric testing- called minimal hepatic encephalopathy (MHE) to profound coma with signs of decerebration. The pathogenesis of hepatic encephalopathy is unknown. Many theories have been proposed; the most frequently discussed is the production of endogenous neurotoxins in particular ammonia. Since the pathogenesis of $\mathrm{HE}$ is mostly due to endogenous neurotoxins produced in the intestine that lack detoxification by the diseased liver, so modification of intestinal flora has been examined as a possible therapeutic option in treatment of HE [7], through different mechanisms, including suppression of harmful micro-organisms or stimulation of beneficial organisms $[8,9]$. And this was reflected in some studies that used probiotics to treat minimal [10,11], episodic [12,13] and grade II HE [14], but none to our knowledge conducted in Egypt. We conducted this study to test the ability of probiotics to treat early grades (minimal and grade I) hepatic encephalopathy.

\section{PATIENTS AND METHODS}

This study was conducted in the Tropical Medicine Department, Zagazig University Hospitals, Egypt. It comprised 100 educated (all finished secondary school education) cirrhotic patients without overt HE. The diagnosis of cirrhosis based on clinical and ultrasonographic examination and laboratory assessment and they were screened for grade-I HE and MHE by psychometric tests. Forty eight educated apparently healthy subjects were also included as controls to determine cut off values of psychometric tests; because psychometric tests are influenced by level of education and culture. Hepatic encephalopathy was diagnosed if at least one of the psychometric tests was abnormal. Thirty patients had abnormal psychometric tests and were included in the final analysis.

\section{Exclusion criteria}

Patients who were illiterate, of grade II and more HE, patients who were exposed to factors that might affect gut flora such as treatment with antibiotics, lactulose, enemas or oral antimicrobials and patients recently receiving antiacids, H2-blockers or proton pump inhibitors were excluded from the study. Also patients with chronic diseases other than cirrhosis e.g. renal failure, uncontrolled diabetes.....etc. were also excluded.

\section{Patient assessment}

All the studied individuals were subjected to:

1- Detailed history taking, with special attention to history of any criterion of the West Haven criteria of altered mental state [15].

2- History of fermented dairy products consumption was taken and subjects who were taking fermented milk were advised to discontinue the intake at least 2 weeks before the study [16].

3- Thorough clinical examination for signs of chronic liver disease.

4- Routine investigations which include liver function tests, prothrombin time (PT), kidney functions, complete blood picture and viral markers.

5- Child-Turcotte-Pugh classing was evaluated for each patient.

6- Abdominal ultrasonographic examination was done to diagnose liver cirrhosis and to detect the presence of ascites.

7- Psychometric tests were done to diagnose the presence of $\mathrm{HE}$ and were repeated after two weeks of Lactobacillus intake.

\section{Probiotic supplementation}

Acidophilus capsule $(10 \mathrm{mg}$ Lactobacillus acidophilus, which contains 100 million active organism, its naturally occurring metabolic product and mixture of rice flour, gelatin and magnesium stearate) was given to the patients 30 minutes before meals 3 times daily (Acidophilus, Walgreens, USA). Banana, as a source of fructooligosacharides was given (in equal amounts to each patient) with each acidophilus capsule 30 minutes before meals. Morelli et al., [16] found that noticeable increase of probiotic count in stools was achieved at the $5^{\text {th }}$ day of oral intake which suggests that potential probiotic benefits can be obtained after only few days of intake, therefore all patients were given probiotic preparation containing Lactobacillus acidophilus for two weeks. Patients who showed no major improvement at two weeks of Lactobacillus intake were advised to take conventional therapy for HE.

\section{Psychometric tests}

The following tests were used for all patients and their results were compared to that of our control subjects 


\section{Circle connection test (CCT)}

The standardized test comprises ten circles of variable sizes distributed on a sheet of paper, and there are five variants of distributions of equal degree of difficulty. The subject is asked to connect the circles according to their sizes by drawing line starting from the smallest circle proceeding to the next larger in size until the largest circle is reached. The test score was the time taken to complete connection of the circles measured in seconds, including the time needed to correct any errors [17]. In this work, CCT was considered abnormal when the time taken by the patients was greater than the mean+2SD from that of the healthy controls (>26 seconds).

\section{Number connection test A (NCT)}

In the NCT, which measures cognitive motor abilities [18], patients must connect numbers from 1 to 25 (written in Arabic, with identification of both the starting and finishing point), printed on a paper as quickly as possible. The test was explained to the subject and a demonstration was shown for him, after he understood the test he was asked to perform it quickly. The test score was the time in seconds required to complete the test, including the time needed to correct any errors. Errors were not enumerated, but patients were instructed to return to the preceding correct number and then carry on. In this work, NCT was considered abnormal when the time taken by the patients was greater than the mean+2SD from that of the healthy controls (>47 seconds).

\section{Digit symbol test (DST)}

It is a subtest of the Wechsler Adult Intelligence Scale-Revised (WAIS) [19]. The patient was given a list of digits from 1 to 9 associated with symbols and was asked to fill in blanks with symbols that correspond to each number. The test score was the total number of correct sequential matching of symbols to numbers in a 90 second interval. After explanation of the test, an abbreviated demonstration was administered to ensure that the patient understood the test correctly. The test was in the Arabic version of the Wechsler Adult Intelligence Scale revised by Meleka [20]. In this work, DST was considered abnormal when the score gained by the patients was less than the mean-2SD from that of the healthy controls $(<29)$.

\section{STATISTICAL ANALYSIS}

Data were checked, entered and analyzed using Epi-Info 2000 for data processing and statistics. Data were expressed as mean \pm SD for quantitative variable, number and percentage for qualitative one. Chi-squared $\left(\mathrm{X}^{2}\right)$ or fisher exact, $\mathrm{t}$ test and paired $\mathrm{t}$ test were used when appropriate. $\mathrm{P}<0.05$ was considered significant.

\section{RESULTS}

In the present work out of 100 educated patients with cirrhosis, 30 patients had HE by psychometric tests. According to West Haven criteria of altered mental state [15], 25 patients (83.3\%) had MHE and 5 patients (16.7\%) had grade-I HE; 2 cases were females $(6.7 \%)$ and 28 cases were males $(93.3 \%)$. All patients in this study were of viral etiology, most of them were due to hepatitis $C$ virus (table 1 ).

CCT, NCT and DST could diagnose 25, 28 and 24 cases respectively; all of them had improved performance after probiotic therapy except one who consumed big amounts of red meat (table 2 ). The number of patients who had normal scores of psychometric tests after the 2 weeks of probiotic therapy was 22,21 and 10 for CCT, NCT and DST indicating a reversal rate of $88 \%$, $75 \%$ and $42 \%$ respectively (table 2 ).

Concerning liver function tests there was a nonsignificant reduction in the serum bilirubin level, ALT level, and PT. Also, there was a nonsignificant increase in serum albumin level after probiotic therapy (table 3 ).

In this study Child-Turcotte-Pugh class improved in 2 cases $(6.7 \%)$ who improved from class $\mathrm{C}$ to class $\mathrm{B}$, while one case (3.3\%) worsened from class B to class $\mathrm{C}$ with no change from class B or $\mathrm{C}$ to class A (table 4).

Although CCT was the most simple test used, it had low sensitivity, specificity, predictive value and diagnostic accuracy (table 6) and it was the least agreed upon screening test for HE in this study (kappa coefficient $=0.75$ ). By the end of the two weeks therapy with Lactobacillus acidophilus, 29 patients (96.7\%) were MHE and only one patient $(3.3 \%)$ remained in grade-I HE, this patient is the same patient who consumed big amounts of red meat as mentioned. No side effects related to Lactobacillus acidophilus intake was reported during the study period. 
Table (1): Characteristics of studied groups.

\begin{tabular}{|c|c|c|c|c|c|c|c|c|}
\hline & \multicolumn{2}{|c|}{$\begin{array}{l}\text { All cirrhotic } \\
\text { patients } \\
(\mathbf{n}=\mathbf{1 0 0}) \\
\end{array}$} & \multicolumn{2}{|c|}{$\begin{array}{c}\text { Patients with } \\
\text { HE } \\
(n=30) \\
\end{array}$} & \multicolumn{2}{|c|}{$\begin{array}{l}\text { Controls } \\
(n=48)\end{array}$} & $\begin{array}{c}\text { Test of } \\
\text { significant }\end{array}$ & $\mathbf{P}$ \\
\hline \begin{tabular}{|c} 
Age (years) \\
$\qquad \begin{array}{l}\overline{\mathrm{X}} \pm \mathrm{SD} \\
\text { (Range) }\end{array}$ \\
\end{tabular} & & & & & & $\begin{array}{l} \pm 9.6 \\
50)\end{array}$ & $\mathrm{t}=1.7$ & $>0.05$ \\
\hline & $\mathbf{n}$ & $\%$ & $\mathbf{n}$ & $\%$ & $\mathbf{n}$ & $\%$ & & \\
\hline Gender & $\begin{array}{l}85 \\
15\end{array}$ & $\begin{array}{l}85 \\
15\end{array}$ & $\begin{array}{c}28 \\
2\end{array}$ & $\begin{array}{c}93.3 \\
6.7\end{array}$ & $\begin{array}{l}37 \\
11\end{array}$ & $\begin{array}{l}77.1 \\
22.9\end{array}$ & $X^{2}=3.51$ & $>0.05$ \\
\hline $\begin{array}{c}\text { Etiology of cirrhosis } \\
\text { Hepatitis B virus } \\
\text { Hepatitis C virus } \\
\text { Hepatitis B \& C } \\
\end{array}$ & $\begin{array}{l}20 \\
60 \\
20\end{array}$ & $\begin{array}{l}20 \\
60 \\
20 \\
\end{array}$ & $\begin{array}{c}6 \\
17 \\
7 \\
\end{array}$ & $\begin{array}{c}20 \\
56.7 \\
23.3 \\
\end{array}$ & & & & \\
\hline $\begin{array}{r}\text { Clinical grade of } \mathbf{H E} \\
\text { Grade-0 } \\
\text { Grade-1 } \\
\end{array}$ & & & $\begin{array}{c}25 \\
5 \\
\end{array}$ & $\begin{array}{l}83.3 \\
16.7 \\
\end{array}$ & & & & \\
\hline $\begin{array}{c}\text { Child-Turcotte-Pugh class } \\
\text { Class A } \\
\text { Class B } \\
\text { Class C } \\
\end{array}$ & $\begin{array}{l}31 \\
39 \\
30\end{array}$ & $\begin{array}{l}31 \\
39 \\
30\end{array}$ & $\begin{array}{c}5 \\
12 \\
13\end{array}$ & $\begin{array}{c}16.7 \\
40 \\
43.3 \\
\end{array}$ & & & & \\
\hline
\end{tabular}

Table (2): Psychometric test scores among patients with HE before and after therapy.

\begin{tabular}{|c|c|c|c|c|c|}
\hline Psychometric test & Before therapy & After therapy & Mean difference & $\mathbf{t}$ & $\mathbf{P}$ \\
\hline 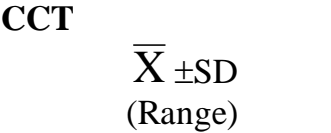 & $\begin{array}{c}33.6 \pm 7.4 \\
(20-58)\end{array}$ & $\begin{array}{c}19.9 \pm 4.4 \\
(12-28)\end{array}$ & $\begin{array}{c}-13.7 \pm 8 \\
(-32: 7)\end{array}$ & 9.34 & $<0.001$ \\
\hline $\begin{array}{ll}\text { NCT } & \\
& \bar{X}_{ \pm S D} \\
& \text { (Range) } \\
\end{array}$ & $\begin{array}{c}64.5 \pm 15.2 \\
(40-99) \\
\end{array}$ & $\begin{array}{c}41.7 \pm 12.3 \\
(28-85) \\
\end{array}$ & $\begin{array}{c}-22.8 \pm 16.4 \\
(-52:-2) \\
\end{array}$ & 7.62 & $<0.001$ \\
\hline $\begin{array}{l}\bar{X} \pm \text { SD } \\
\text { (Range) }\end{array}$ & $\begin{array}{c}21.7 \pm 8.1 \\
(8-45) \\
\end{array}$ & $\begin{array}{c}29.9 \pm 8.1 \\
(19-51) \\
\end{array}$ & $\begin{array}{l}8.1 \pm 4.9 \\
(-5: 17) \\
\end{array}$ & 9.05 & $<0.001$ \\
\hline
\end{tabular}

Table (3): Liver function tests before and after therapy among studied patients with HE.

\begin{tabular}{|c|c|c|c|c|c|}
\hline Liver function test & Before therapy & After therapy & Difference & $t$ & $\mathbf{P}$ \\
\hline $\begin{array}{c}\text { Total bilirubin (mg/dl) } \\
\overline{\mathrm{X}} \pm \mathrm{SD} \\
\text { (Range) }\end{array}$ & $\begin{array}{c}2.58 \pm 1.96 \\
(0.48-8.84)\end{array}$ & $\begin{array}{c}2.44 \pm 1.67 \\
(0.57-7.8)\end{array}$ & -0.13 & 0.53 & 0.60 \\
\hline \begin{tabular}{|c} 
Albumin $(\mathbf{g m} / \mathbf{d l})$ \\
$\overline{\mathrm{X}} \pm \mathrm{SD}$ \\
(Range) \\
\end{tabular} & $\begin{array}{c}2.9 \pm 0.7 \\
(2.1-4.5) \\
\end{array}$ & $\begin{array}{c}3.1 \pm 0.7 \\
(2.2-4.7) \\
\end{array}$ & 0.15 & 1.36 & 0.18 \\
\hline $\begin{array}{r}\text { PT (in seconds) } \\
\overline{\mathrm{X}} \pm \mathrm{SD} \\
\text { (Range) } \\
\end{array}$ & $\begin{array}{c}18.5 \pm 4.2 \\
(11-31)\end{array}$ & $\begin{array}{c}18 \pm 2.99 \\
(13.1-27)\end{array}$ & -0.4 & 0.95 & 0.64 \\
\hline $\begin{array}{r}\text { ALT (IU/L) } \\
\overline{\mathrm{X}} \pm \mathrm{SD} \\
\text { (Range) } \\
\end{array}$ & $\begin{array}{c}52.3 \pm 18.2 \\
(24-109)\end{array}$ & $\begin{array}{c}49.4 \pm 14.8 \\
(20-82)\end{array}$ & -2.9 & 1.39 & 0.17 \\
\hline
\end{tabular}


Table (4): Child-Turcotte-Pugh classes before and after therapy among patients with HE.

\begin{tabular}{|c|c|c|c|c|c|}
\hline \multirow{2}{*}{ Child-Turcotte-Pugh class } & \multicolumn{2}{|c|}{ Before therapy } & \multicolumn{2}{|c|}{ After therapy } & \multirow{2}{*}{ P* } \\
\cline { 2 - 5 } & No. & \% & No. & \% & \\
\hline A & 5 & 16.7 & 5 & 16.7 & $>0.05$ \\
\hline B & 12 & 40.0 & 13 & 43.3 & \\
\hline C & 13 & 43.3 & 12 & 40.0 & \\
\hline
\end{tabular}

*Mc Nemar's chi-square test

Table (5): Relationship between psychometric tests and Child-Turcotte-Pugh classes.

\begin{tabular}{|l|c|c|c|c|c|c|}
\hline & $\begin{array}{c}\text { Class A } \\
\mathbf{n = 5}\end{array}$ & $\begin{array}{c}\text { Class B } \\
\mathbf{n = 1 2}\end{array}$ & $\begin{array}{c}\text { Class C } \\
\mathbf{n = 1 3}\end{array}$ & $\begin{array}{c}\text { Total } \\
\mathbf{n = 3 0}\end{array}$ & $\mathbf{X}^{\mathbf{2}}$ & $\mathbf{P}$ \\
\hline Patients who were diagnosed by CCT & 5 & 8 & 12 & 25 & 4.15 & 0.12 \\
\hline Patients who were diagnosed by NCT & 4 & 12 & 12 & 28 & 2.31 & 0.31 \\
\hline Patients who were diagnosed by DST & 3 & 9 & 12 & 24 & 2.67 & 0.26 \\
\hline Patients who were abnormal in all test & 3 & 8 & 11 & 22 & 1.57 & 0.45 \\
\hline
\end{tabular}

Table (6): Validity of psychometric tests.

\begin{tabular}{|c|c|c|c|c|c|c|c|c|}
\hline & & \multirow[b]{2}{*}{ Cases } & \multirow{2}{*}{$\begin{array}{c}\text { Sensitivity } \\
\%\end{array}$} & \multirow{2}{*}{$\begin{array}{c}\text { Specificity } \\
\%\end{array}$} & \multicolumn{2}{|c|}{ Predictive value \% } & \multirow{2}{*}{$\begin{array}{c}\text { Kappa of } \\
\text { agreement }\end{array}$} & \multirow{2}{*}{$\begin{array}{c}\text { Diagnostic } \\
\text { accuracy } \\
\%\end{array}$} \\
\hline & & & & & Positive & Negative & & \\
\hline CCT & $\begin{array}{l}>26 \text { seconds } \\
\leq 26 \text { seconds }\end{array}$ & $\begin{array}{c}25 \\
5\end{array}$ & 83.3 & 91.7 & 86.3 & 89.8 & 0.75 & 88.5 \\
\hline NCT & $\begin{array}{l}>47 \text { seconds } \\
\leq 47 \text { seconds }\end{array}$ & $\begin{array}{c}28 \\
2 \\
\end{array}$ & 93.3 & 97.9 & 96.6 & 95.9 & 0.92 & 96.2 \\
\hline DST & $\begin{array}{l}<29 \\
\geq 29\end{array}$ & $\begin{array}{c}24 \\
6\end{array}$ & 80.0 & 100 & 100 & 88.9 & 0.83 & 92.3 \\
\hline
\end{tabular}

- CCT was considered abnormal if the patient took more than 26 seconds.

- NCT was considered abnormal if the patient took more than 47 seconds,

- DST was considered abnormal if the patient scored less than 29.

\section{DISCUSSION}

Minimal HE was reported, world wide, to be present in $10 \%$ to $84 \%$ of cirrhotic patients without overt $\mathrm{HE}$, depending on the diagnostic techniques used and patients selected for the studies [21]. In contrast to patients with symptomatic HE, patients with MHE have no recognizable symptoms of brain dysfunction [22]. MHE was assumed to have a negative effect on patients' daily functioning because psychomotor rather than verbal abilities tend to be affected and therefore treatment is recommended [3,23] and is regarded as a prophylactic measure against development of overt HE [24]. Patients with MHE are in need for close monitoring because of the fear to develop overt $\mathrm{HE}$; more than $50 \%$ of them develop overt $\mathrm{HE}$ within a short period of time [24].

Clinicians may have difficulty in distinguishing patients with grade-I $\mathrm{HE}$ from patients with minimal HE [25]. That is why patients of grade 0 (MHE) and grade I were analyzed together in this study. In our study it occurs at a frequency of $30 \%$ in cirrhotic patients.

No study, to our knowledge, evaluated the effect of probiotics on early grades of HE in Egyptian cirrhotic patients. But Liu et al. [10] evaluated synbiotic modulation of gut flora on $\mathrm{MHE}$ in Chinese patients. They used synbiotic preparation consisting of 4 freeze-dried, nonurease producing bacteria, namely Pediacoccus pentoseceus 5-33:3, Leuconostoc mesenteroides 32-77:1, Lactobacillus paracasei 19, Lactobacillus plantarum 2592, along with a fermentable fiber preparation consisting of glucan, inulin, pectin and resistant starch. They evaluated the effect of synbiotics on 58 cirrhotic patients with MHE.. Patients were given synbiotic preparation for one month. Evaluation of therapy was done with the aid of NCT, brainstem evoked potentials and Child-TurcottePugh classification. They found improvement of Child-Turcotte-Pugh class, improvement of MHE, improvement of liver functions, improvement of evoked potentials and NCT with 
a positive correlation between NCT and ChildTurcotte-Pugh class. The discrepancies in the results between our study and that of Liu et al. may be due to: (1) all our cases are of viral etiology compared to $74 \%$ in their study, (2) longer duration of therapy one month in their study and two weeks in our study, (3) multiple probiotic strains they used compared to one strain in this study and (4) many fermentable prebiotics fibers they used. They reported that none of their patients developed overt hepatic encephalopathy during their study. Although the same applies to the present study yet no meaningful conclusion can be drown from those observations as the duration of the study was 4 weeks in the study of Liu et al. and 2 weeks in the present study.

Also Saji et al. [11] evaluated probiotics on Indian cirrhotic patients with MHE. They received a probiotic preparation in a dose of one gram sachet containing not less than 1.25 billion spores of Lactobacillus acidophilus, Lactobacillus rhamnosus, Bifidobacterium longum and Sacharomyces boulardi, three times daily after meals. Diagnosis of MHE based on NCT-A, evoked potentials and arterial ammonia level and they were treated for 4 weeks before re-assessed by the same tests. By the end of treatment duration they failed to demonstrate any benefit for probiotics over placebo. Furthermore, liver functions were not assessed in this study. When compared to our study; most of their patients were of alcohol etiology; and alcoholics are known to relapse and deny that, also our patients were all inpatient with close monitoring.

Improvement of liver functions in this study and other studies concerned with the use of probiotics in liver diseases may be due to decreased exposure of the liver to inflammatory mediators, oxidative stresses and endotoxins released from the GIT [26-28].

None of our patients developed overt HE or adverse effects related to the probiotics during the study period and this is probably due to: (1) all patients in the present work were hospitalized, (2) none of them was alcoholic, (3) all of them were closely monitored, (4) all clearly instructed to avoid exposure to precipitants of $\mathrm{HE}$ and (5) safety of the probiotic strain we used, none of our cases developed adverse effects due to intake of Lactobacillus acidophilus.

Our results cope with the doubt in the ability of probiotics to improve viral induced liver damage. Although in this study Child-Turcotte-Pugh score showed improvement at the end of the two weeks period of therapy when compared to pretreatment period this improvement was nonsignificant, this is secondary to the nonsignificant improvement in liver functions

Psychometric tests were used in detection and follow up of HE. Circle connection test can be done quickly and easily more than NCT and it also can be used by illiterate subjects [29]. NCT and DST were used in this work because they are simple, inexpensive and sensitive and have been evaluated in several studies for their value in the diagnosis, prognosis and treatment of $\mathrm{HE}$ $[30,31]$. In addition of its simplicity, NCT is relatively unaffected by patient's level of learning [32].

In Egyptian cirrhotic patients screened with psychometric tests, NCT had positive predictive value of $96.6 \%$ and negative predictive value of $95.9 \%$ and greater diagnostic accuracy $(96.6 \%)$ compared to other psychometric tests used. NCT is the most sensitive test used to diagnose HE, and it had high significance agreement among the screening tests (CCT, NCT and DST) used for diagnosis of HE (kappa coefficient $=0.92$ ). These results agree with Amodio et al. [33] who confirmed the efficacy of NCT as a simple tool in assessing cognitive alterations in cirrhosis. DST was the highest specific test in this study; it had specificity of $100 \%$, sensitivity of $80 \%$, positive predictive value of $100 \%$, and negative predictive value of $88.9 \%$ and diagnostic accuracy of $92.3 \%$. These results are in agreement with $\mathrm{Li}$ et al. (2004) [21] who concluded that DST and NCT test battery was sensitive and specific for detection of MHE.

\section{CONCLUSIONS}

Probiotics could be used to treat early grades of HE. Child-Turcotte-Pugh class of cirrhotic patients and liver functions did not improve significantly after probiotic therapy. Psychometric tests (CCT, NCT and DST) are valid as screening tests for $\mathrm{HE}$ in Egyptian patients.

\section{Funding: Non.}

\section{Conflicts of interest: Non.}

Ethical approval: The protocol of the study was approved by the ethical committee of Faculty of Medicine, Zagazig University. Informed consents were obtained from all patients. 


\section{REFERENCES}

1. Havenar R, Huis In't Veld JH. Probiotics: a general view. Wood $B$ eds. The Lactic acid Bacteria in Health and Disease 1992: 209. Elsevier applied science London UK.

2. Fooks LJ, Gibson GR. Probitics as modulators of the gut flora. British J Nutr 2002; 88:39

3. Gerber T, Schomerus H. Hepatic Encephalopathy in Liver Cirrhosis: Pathogenesis, Diagnosis and Management. Drugs 2000; 60:1353.

4. Ng SC, Hart AL, Kamm MA, Stagg AJ, Knight SC. Mechanisms of Action of Probiotics: Recent Advances. Inflamm Bowel Dis. 2009;15(2): 300310.

5. Quigley, E. and Quera, R. Small intestinal bacterial overgrowth: roles of antibiotics, prebiotics, and probiotics. Gastroenterology. 2006;130(2 Suppl 1): S78 - 90.

6. Rolfe, R.D. The role of probiotic cultures in the control of gastrointestinal health. J. Nutr. 2000; 130: 396.

7. Bongaerts G, Sverijnen R, Timmerman H. Effect of antibiotics, prebiotics and probiotics in treatment for hepatic encephalopathy. Med Hypotheses 2005; 64: 64.

8. Fuller R, Gibson GR. Modifications of the intestinal microflora using probiotics and prebiotics. Scand J Gastroentrol Suppl 1997; 222:28.

9. Salminen S, Isolauri E, Salminen E. Clinical uses of probiotics for stabilising gut mucosal barrier: successful strains and future challenge. Antonie Van Leeuwenhock 1996; 70: 347.

10. Liu Q, Duan Z P, Ha D K Bengmark S, Kurtovic J, Riordan SM.. Synbiotic Modulation of Gut Flora: Effect on Minimal Hepatic Encephalopathy in Patients With Cirrhosis. Hepatology 2004; 39: 1441.

11. Saji S, Kumar S, Thomas V. A randomized double blind placebo controlled trial of probiotics in minimal hepatic encephalopathy. Trop Gastroenterol. 2011;32(2):128-32.

12. Macbeth WA, Kass EH, Mc Dermott WV. Treatment of hepatic encephalopathy by alteration of intestinal flora with Lactobacillus acidophilus. Lancet 1965; 1:399.

13. Read AE, Mc Carthy CF, Heaton KW, Laidlaw J. Lactobacillus acidophilus ( Enpac) in treatmrnt of hepatic encephalopathy. BMJ 1996; 1: 1267.

14. Loguercio C, Abbiati R, Rinaldi M, Romano A, Del Vecchio Blanco C, Coltorti M. Long term effects of Enterococcus faecium SF68 versus lactulose in treatment of patients with cirrhosis and grade 1-2 hepatic encephalopathy. J Hepatol 1995; 23:39.

15. Atterbury CE, Maddery WC, Conn HO. Neomycin-sorbitol and lactulose in the treatment of acute portal systemic encephalopathy. A controlled, double-blind clinical trial. Am J Dig Dis 1978, 23: 398.
16. Morelli L, Zonenschain D, Callegari ML, Grossi E, Maisano F, Fusillo M. Assessment of a new synbiotic preparation in healthy volunteers: Survival, persistence of probitic strains and its effect on the indigenous flora. Nutr J 2003; 2: 11.

17. Hassen RM. Bromocriptine in hepatic encephalopathy. M.Sc. Thesis. Tropical Medicine. Zagazig university 1989:70.

18. Sood GK, Sarin SK, Mahaptra J, Broor SL. Comparative efficacy of psychometric tests in detection of subclinical hepatic encephalopathy in alcoholic cirrhotics: search for rational approach. Am J Gastroenterol 1989; 84: 156.

19. Wechsler D. Wechsler Adult Intelligence ScaleRevised. New York: Psychological Corp, 1981.

20. Meleka M K. Wechsler Adult Intelligence ScaleRevised in Arabic. $1^{\text {st }}$ edition, Maktabat-Elnahda El-Masria. Cairo, 1983.

21. Li YY, Nie YQ, Sha WH, Zeng Z, Yang FY, Ping $L$ et al. Prevalence of subclinical hepatic encephalopathy in cirrhotic patients in China. World J Gastroenterol 2004; 10: 2397.

22. Ferenci P, Lockwood A, Mullen K, Tarter R, Weissenborn K, Blei AT. Hepatic encephalopathy- definition, nomenclature, diagnosis, and quantification : Final report of the working party at the $11^{\text {th }}$ World Congress of Gastroenterology, Vienna, 1998. Hepatology 2002; 35: 716.

23. Groeneweg M, Quero JC, De Bruijn I, Hartmann IJ, Essink-bot ML, Hop WC et al. Subclinical Hepatic Encephalopathy Impairs Daily functioning. Hepatology 1998; 28: 45.

24. Saxena N, Bhatia M, Joshi YK, Garg PK, Dwivedi SN, Tandon RK. Electrophysiological and neuropsychological tests for the diagnosis of subclinical hepatic encephalopathy and prediction of overt encephalopathy. Liver 2002; 22:190.

25. Solga SF. Probiotics can treat hepatic encephalopathy. Med Hypotheses 2003; 61: 307.

26. Nolan JP. Intestinal endotoxin as mediators of hepatic injury-an idea whose time has come again. Hepatology 1989; 10:887.

27. Li Z, Yang SQ, Lin HZ, Huang J, Watkins PA, Moser AB et al. Probiotics and antibodies to TNF inhibit inflammatory activity and improve nonalcoholic fatty liver disease. Hepatology 2003; 37:343.

28. Solga SF, Diehl AM. Gut Flora- Based Therapy in Liver Disease? The Liver Cares About the Gut. Hepatology 2004; 39: 1197.

29. El-Amin HM. Circle connection test. M. Sc. Thesis . Psychology. A method for measuring cerebral dysfunction in patients with chronic liver disease. Zagazig University 1985:109

30. Sood GK, Sarin SK, Mahaptra J, Broor SL. Comparative efficacy of psychometric tests in detection of subclinical hepatic encephalopathy in alcoholic cirrhotics: search for rational approach. Am J Gastroenterol 1989; 84: 156.

31. Schomerus H, Weissenborn K, Hanster W, Rückert N, Hecker H. PSE-Syndrome-Test 
manual, Swets Test Services. Frankfurt: Swets\& Zeitlinger BV, 1999.

32. Zeneroli M, Cioni G, Ventura P , Russo AM, Venturini I, Casalgrandi G, Ventura E. Interindividual variability of the number connection test. J Hepatol 1992; 15: 263.
33. Amodio P, Del Piccolo F, Marchetti P, Angeli P, Iemmolo R, Caregaro L et al. Clinical features and survival of cirrhotic patients with subclinical cognitive alterations detected by the number connection test and computerized psychometric tests. Hepatology 1999; 29:1662. 